\title{
Evaluation of Protective Effect of Ajwa Seed And Fruit on Renal Histopathological Changes in Diabetic Nephropathic Rats
}

\section{Iram Imran, ${ }^{1}$ Maryam Mansoor, ${ }^{2}$ Farwa Naqvi, ${ }^{3}$ Mahreen Akhtar, ${ }^{4}$ Waleed Arshad, ${ }^{5}$ Faiza Khan $^{6}$}

\begin{abstract}
Objective: To investigate the protective effect of Ajwa date seed and fruit on renal histological changes in alloxan induced diabetic rats.

Methods: This was an experimental study and was conducted in Post Graduate Medical Institute. The duration of study was 6 weeks. In this study random allotment of 32 rats was done in four groups. Group 1 was treated as control. Diabetes was induced in the $2 \mathrm{nd}$, 3rd and 4th group by alloxan injection intra peritoneally. Group 2 was diabetic non treated while group 3 and 4 were treated with Ajwa seed and flesh respectively. After six weeks, animals were anaesthetized and kidneys were then removed without delay and weighed. Kidney paraffin sections were prepared and stained with hematoxylin\& eosin (H\&E) and with Periodic acid Schiff (PAS) technique. Glomerular diameters were estimated. Glomerular volume determined by stage micrometer. Vascular, tubular injury and glomerular sclerosis were studied semi quantitatively.

Results: The data showed that Ajwa date seed significantly reduced hyperglycemia but did not normalize the fasting blood glucose. We found exceedingly significant improvement in kidney weight, glomerular diameter, tubular and vascular injury with Ajwa date seed suggesting reduction in diabetic nephropathy. Ajwa seed diet found more effective in reducing nephropathy than Ajwa fruit diet. Current study displayed that the seed of Ajwa showed significant improvement in renal histological characteristics in diabetic rats.

Conclusion: The findings showed that Ajwa date seed and flesh reduce loss of tubular and vascular damage in alloxan induced diabetes.

Key Words: Oxidative stress, Kidney, Diabetes, Ajwa, Antioxidant, histopathology

How to cite: Imran I., Mansoor M., Naqvi F., Akhtar M., Arshad W., Khan F. Evaluation of protective effect of Ajwa seed and fruit on renal histopathological changes in diabetic nephropathic rats. Esculapio 2021;17(01):104-109

DOI: https://doi.org/10.51273/esc21.2517121
\end{abstract}

\section{Introduction}

$\mathrm{D}$ iabetic nephropathy is the main cause of chronic kidney failure. The International Diabetic Federation stated a number of 440 million diabetics in the year 2015 which is anticipated to rise 550 million

$\begin{array}{lll}\text { 1. Iram Imran } & \text { 2. } & \text { Maryam Mansoor } \\ \text { 3. Farwa Naqvi } & \text { 4. } & \text { Mahreen Akhtar } \\ \text { 5. Waleed Arshad } & \text { 6. Faiza Khan } \\ \text { 1,4,5. Department of Pharmacology \& Therapeutics, Amna Inayat Medical } \\ \text { College, Sheikhupura }\end{array}$
$\begin{aligned} & \text { 2. Pharmacology \& Therapeutics, Al Aleem Medical College Gulab Devi } \\ & \text { Hospital, Lahore }\end{aligned}$
$\begin{aligned} & \text { 3. Pharmacology \& Therapeutics, Sargodha Medical College, Sargodha } \\ & \text { 6. Pak Red Crescent Medical \& Dental College, Dina Nath. }\end{aligned}$

\section{Correspondence:}

Dr. Iram Imran, Department of Pharmacology \& Therapeutics, Amna Inayat Medical College, Sheikhupura

Email: iramimran49@gmail.com

$\begin{array}{ll}\text { Submission Date: } & 12-11-2020 \\ \text { 1st Revision Date: } & 09-12-2020 \\ \text { 2nd Revision Date: } & 10-01-2021 \\ \text { Acceptance Date: } & 13-02-2021\end{array}$

by the year 2035 . About $35 \%$ of diabetic patients observe renal disorders. Prolonged glycemia, race, sex, genetics and hypertension have been involved in the development of nephropathy in diabetes. ${ }^{1}$ In Diabetic nephropathy, hyperfiltration progresses into macroalbuminuria and glomerular endothelial dysfunction leading to decrease in glomerular filteration rate and end stage kidney disease. ${ }^{2}$

Reactive oxygen species, inflammatory cytokines and growth factors are key players in this respect. ${ }^{3}$ Most of the studies reveal the implication of oxidative stress in diabetes pathogenesis by the alteration in different signaling pathways like renin angiotensin system, development of advanced glycation end products, lipid peroxidation, impaired glutathione metabolism and decreased levels of Vit C, lipids, glutathione peroxidase, catalase, superoxide dismutase, DNA damage are various indicators of oxidative 
stress in diabetes mellitus. Oxidative stress causes insulin resistance also. ${ }^{4}$ Hyperglycemia in kidney tissue induces mesengial expansion and causes changes in cellular and extra cellular glomerular structure, presented by glomerular basement membrane thickening, increased glomerular volume, diameter and glomerulosclerosis.

Anti-diabetic drugs which are commonly used in the treatment of type 2 diabetes mellitus are sulfonylureas, biguanides, thiazolidinediones and $\alpha$ glucosidase inhibitors. None of these is devoid of adverse effects for example sulfonlyureas carries risk of hypoglycemia, drug allergy and drug resistance when used for longer period of time. Biguanides can lead to diarrhea and lactic acidosis where as TZD carries risk of mild anemia and edema and may increase the risk of heart failure. Phonex dactylefera L. (Palmaceae) is grown mostly in Middle East and United States. Date fruit is used in diet as traditional medicine in many countries. Our previous studies have confirmed that date fruit and seeds have shown multiple bioactivities like antihyperglycemic ${ }^{7}$ and anti-nephropathic activities when given for 6 weeks to alloxanized rats because of having phytoelement like antioxidants, phenolics, flavonone, anthocynins. Previously published researches found the nephroprotective effects of $p$ dactylefera. ${ }^{8,9}$ So considering the traditional use of date palm in the treatment of diabetes mellitus and in its complications, this study was carried out to investigate the protective effect of Ajwa date seed and fruit on histological alterations of kidneys in alloxan induced diabetic nephropathy.

\section{Methods}

Experimental study in Post Graduate Medical Institute Lahore for period of six weeks duration.

\section{Ajwa collection and preparation of diet:}

Two kilograms of Ajwa date was bought from Khajoor market Madina (Saudi Arabia). Department of botany - Govt. College Lahore identified and preserved specimen in herbarium after allotting voucher number (Herb.2954). The seeds were separated, washed, air dried and ground to form powder while fruit was cleaned and mashed finely. They were kept in air tight jars, labeling was done and stored in cool dry place for further use.

\section{Animals}

Thirty two Sprague dawley rats (healthy male) were purchased from University of health sciences Lahore and divided into four groups (8 rats per group). They were kept in animal laboratory, Post graduate medical institute, Lahore. Controlled environmental temperature was sustained with $12 \mathrm{hr}$ light and day cycle alternatively. Regular pallet diet mixed with rat chow and water was given ad libitum. Prior Approval of the current study was taken from ethical committee of Post graduate medical institute and advance board, university of health sciences, Lahore

\section{Induction of experimental diabetes}

Alloxan was freshly dissolved in normal saline just before use and given as a single intraperitoneal injection $(150 \mathrm{mg} / \mathrm{kg})$ to fasting rats of all groups except normal control. After about 72 hours, animals showing blood glucose fasting level $>250$ and $<500$ were chosen as diabetics and divided into four groups for study.

\section{Dosage and treatment protocol:}

Group I is normal control and normal saline single intraperitoneal injection was given. Rats from Group II, III and IV were given intraperitoneally, the alloxan monohydrate injection $(150 \mathrm{mg} / \mathrm{kg})$. Group II was kept as diabetic control group. Ajwa seed powder (1.5 g) and Ajwa fruit $(7 \mathrm{~g})$ were mixed to 100 gram of rat chow individually, small pallets were made and this diet was given to animals of group III \& IV for six weeks continuously ad libitum after confirmation of diabetes. This every day diet requirement for rats was proposed on the basis of recommendations from Ahadith regarding the daily requirement for adult human being is seven dates. ${ }^{10}$

\section{Determination of relative kidney weight and fasting blood glucose}

Fasting blood glucose level was determined by the glucometer (Roche Accucheck performa).

\section{Histological assessment of kidneys}

After sacrificing rats, kidneys were taken out, weighed and fixed in buffered formalin (10\% neutral). After fixation, tissue sections $(5 \mu \mathrm{m})$ were cut and embedded in paraffin wax.

Tissue sections were then stained with hematoxylineosin (H\&E) and assessment of vascular and tubular injury was made under light microscope at $400 \mathrm{X}$ magnifications. Periodic Acid Schiff staining was 
used to see the thickness of basement membranes of glomeruli, mesengial matrix and glomerulosclero$\operatorname{sis}^{11}$. The slides were analyzed blindly by pathologist who designated the vascular, tubular injury, thickening of basement membrane and matrix on the scale: 0, absent; 1 , negligible; 2 , moderate; 3 , severe.

Semi quantitative range was applied to study glomerulosclerosis, where 0 designated normal glomeruli, 1 designated sclerosis equal to $25 \%$ of glomeruli, and 2 equal to $25-50 \%, 3$ equal to $50-75 \%$ and 4 equal to sclerosis in more than $75 \%$ of glomeruli. ${ }^{12}$

Glomerular diameters were measured by selecting randomly about50-60 glomeruli in each kidney by stage method using oculomicrometer. Calibration value was calculated for one division of oculomicrometer. Two measurements, one cross wise and other right angle to it were measured and its mean was taken for diameter of one glomerulus. ${ }^{13}$

\section{Statistical Analysis:}

Histological parameters were presented with percentages. ANOVA (Kruskal Wallis) was applied to study the significance of effects in all study groups. Pair wise assessment and comparison of histopathological variables between groups was made by Mann Whitney U test.

\section{Results}

\section{Treatment with Ajwa seed nearly normalized} relative kidney weight and glomerular diameter

Relative kidneys weights were found highly significantly elevated ( $p$ 0.001) in diseased group when compared to control rats. Treatment with Ajwa seed highly significantly $(0.01)$ lowered the relative kidney weights with comparison to diabetic rats. Effect of Ajwa fruit was not significant.

Glomerular diameters were found significantly increased ( $p$ 0.001) in diabetic group. Treatment with Ajwa seed highly significantly (p0.001) restored the glomerular diameter as compared to diabetic group. Ameliorative effect of Ajwa fruit was not significant (Table 1).
Treatment with Ajwa seeds and fruit alleviated histopathological injuries in diabetic rats

Examination of kidney histopathology revealed normal kidney histology in the control group (figure 1a). The untreated diabetic kidneys, compared to control group showed marked vascular, tubular injury and glomerulosclerosis in more than $50-70 \%$ of glomeruli (Fig 1b). Glomerular capillaries were irregular, widened and attached to bowman's capsule. Tubointerstitial damage was severe. There were only few widened tubules with early atrophy of epithelial cells. Moderate interstitial fibrosis was also observed. There was thickening of basement membranes and mesengial matrix as well as increase in the number of mesengial cells.

Treatment with Ajwa seed highly significantly alleviated tubular injury, improved the thickening of basement membrane, mesengial matrix and glomerulosclerosis (all p 0.01) and vascular injuries ( $\mathrm{p}$ 0.001 ) compared with untreated diabetic group (Fig 1c). Similarly Ajwa fruit treated group also showed significant improvement in all of above histological injuries (all p0.05).Ajwa fruit treatment alleviated glomerulosclerosis but effect was not significant when compared to diseased group.

\section{Discussion}

P. dactylefera fruit and seeds have been consumed in folk medicine since long ago for treatment of diabetes mellitus. Few studies have demonstrated their antidiabetic effects but a lesser amount of data has been available to see the effect of seeds and fruit of dates on diabetic complications like nephropathy. The current study was carried out to probe the effects of Ajwa seed and fruit on nephropathy and histopathological changes of diabetic kidneys.

Most severe complication of diabetes is nephropathy and researchers have reported that progressive protein urea causes gradual declining of kidney function parameters which is the major risk factor for progre-

Table 1: Relative Kidney Weights \& Glomerular Diameters

\begin{tabular}{|c|c|c|c|c|}
\hline Parameter & Control & Diabetic & $\begin{array}{c}\text { Diabetics on Ajwa } \\
\text { seed diet }\end{array}$ & $\begin{array}{l}\text { Diabetics on Ajwa } \\
\text { fruit diet }\end{array}$ \\
\hline Relative kidney weight(g/100g body weight) & $0.413 \pm 0.025$ & $0.581 \pm .073^{\# \# \#}$ & $0.46 \pm 0.74^{* *}$ & $0.55 \pm 0.07$ \\
\hline Glomerular diameter & $96.2 \pm 0.6$ & $121.5 \pm 6.0^{\# \# \#}$ & $105.4 \pm 8.4^{* * *}$ & $112.1 \pm 9.7$ \\
\hline
\end{tabular}

Table 1: Treatment with both Ajwa seed and fruit almost normalized relative kidney weight and glomerular diameter. Data is shown as Mean $\pm \mathrm{SD} . \mathrm{n}=8 .{ }^{* *}$ and $* * *$ numerical difference as compared to diabetic group at $\mathrm{p}<0.01$ and $\mathrm{p}<0.001$ respectively. \#\# and \#\#\# numerical difference as compared to control group at $\mathrm{p}<0.01$ and $\mathrm{p}<0.001$ respectively 
ssive renal impairment. Diabetic nephropathy is also related with increase in relative kidney weight, glomerular diameter, tubular damage, vascular injury and glomerulosclerosis. ${ }^{3}$

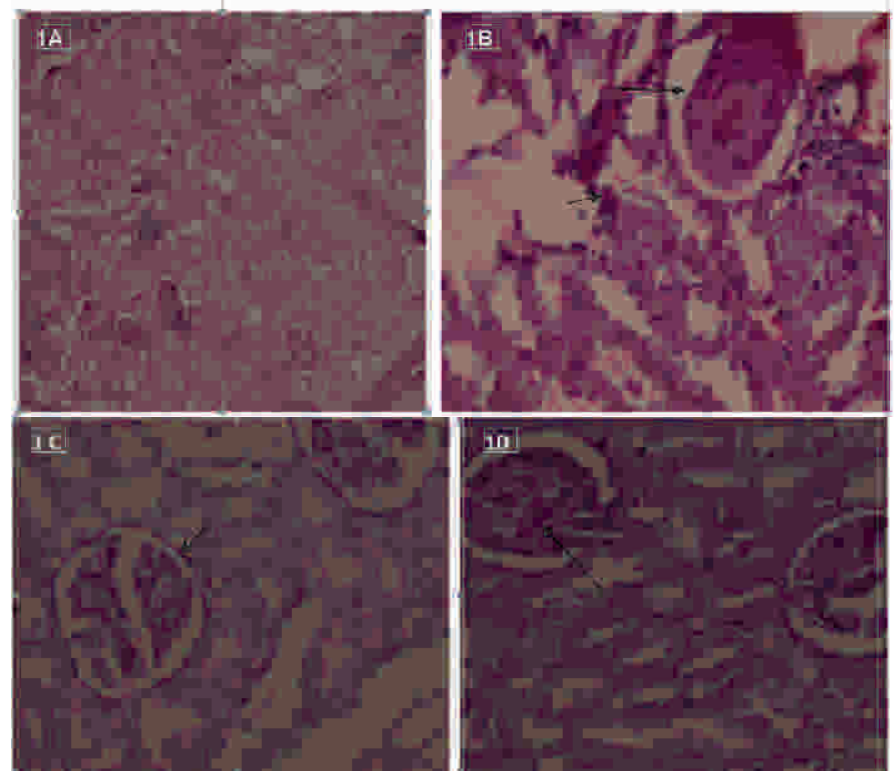

Fig 1: Histopathological Changes in Kidneys of Control and Experimental rats.(1A-Group I) Normal Kidneys with Normal Glomeruli \& Tubules - H\&E 100X.(1B-Group II) Diabetic Kidneys Showing Severe Angiopathy, Thickening of Basement Membrane and Diffusely Moderate Glomerulosclerosis - PAS 400X. (1C-Group III) Ajwa Seeds Nearly Normalized renal Histology. Minimal Glomerular Changes are Seen - PAS 400X. (1DGroup IV) Ajwa Fruit Showed Less Significant Effect. Moderate Changes in Glomeruli and Tubules are Visible-PAS 100X.

In current study, treatment with Ajwa seed and fruit ameliorated relative kidney weight and glomerular size. Our findings are in line with results of Abdelaziz who reported that treatment with Hayani seed aqueous suspension restored the relative weight of kidneys in streptozotocin induced diabetes in rats in 4 weeks time.'

Our results of other histopathological indicators showed noticeable presence of capillary congestion, mesengial and glomerular hypertrphy, tubointerstitial fibrosis, glomerular basement membrane thickening along with fairly diffuse glomerulosclerosis in diseased group as compared to control.

Our results are comparable to a study in which oxidative stress produced by alloxan caused svere diabetes. Prolonged hyperglycemia and severe oxidative stress in untreated diabetes lead to micro as well as macro- angiopathy. Renal vacuolar changes occurred in tubular cells, glomerular mesengium increased and average weight of kidney and size of glomeruli increased in diabetes mainly due to glycogen accumulation, protein synthesis and lipogenesis. Process of glycation lead to degradation of extra cellular matrix and tubointerstitial fibrosis. ${ }^{14}$

Treatment with Ajwa seed markedly improved all histological parameters while Ajwa fruit showed minimal to modest improvement in histological characteristics of renal injury. Our results are comparable to a latest study in which researcher found out that date seed powder suspension restored normal architecture of glomeruli and tubules in diabetic nephropathy by streptozotocin. ${ }^{9}$ Previously Ali A demonstrated that Ajwa flesh alleviated Ochratoxin induced tubointerstitial injury. ${ }^{15}$

Few other researches foundout the preservation of renal tubular epithelial lining along with alleviation of angiopathy and proximal tubular damage in renal injury by carbon tetrachloride and gentamycin respe ctively. ${ }^{16,17}$

A massively growing data has demonstrated that $p$ dactylefera is rich in antioxidants and has immense free radical scavanging activities. Date fruits and seeds both are rich in most excellent absorbable polyphenols, carotenoids, minerals and flavonones and all of these have strong antioxidant potential. ${ }^{18}$ Polyphenols have proved their efficacy in treating diabetic complications in previuos studies P-coumaric acid, gallic acid and cinnamic cids are key phenols and present up to $35.9 \mathrm{mg}$ caffeic acid equavalentin per 100 gram fresh weight. ${ }^{19}$ Dates seeds have shown their ability to enhance antioxidative enzymes in body like catalase, glutathione-transferase and superoxide dismutase. ${ }^{9}$

Ethnobotanical research data found that Ajwadate contain maximum nutrients, antioxidants and polyphenols. Zinc $(1.91 \mathrm{mg} / \mathrm{g})$, potassium $(7.4 \mathrm{mg} / 100 \mathrm{~g})$, magnesium (59mg/100g), calcium (57.5.g/ 100g), iron $(23.5 / 100 \mathrm{~g})$ and phosphorus $(7.3 \mathrm{mg} / 100 \mathrm{~g})$ are the main minerals present in large quantity in Ajwa seed and flesh. ${ }^{20}$ Ajwa pits have remarkable amounts of polyphenols as compared to fruit. ${ }^{21}$ Ajwa flesh has highest nitric oxide scavenging activity ${ }^{22}$ while seed extracts of Ajwa is highest in DPPH (3932mgGAE/ $100 \mathrm{~g})$ \& ABTS $(2956 \mathrm{mgQEC} / 100 \mathrm{~g})$ activity compared to fruit.21Active flavonoids present in Ajwa seed and fruits are Iso-quercetin, apigenin, quercitin, 
luteolin and rutin. ${ }^{23}$ Natural polyphenols and rutin have already established their role in prevetion of diabetes millitus through effctive antioxidant activities. $^{24}$

Researchers found the immence improvement by quercetin alone and along with insulin in tubular necrosis and glomerular basement thickening in streptozotocin provoked diabetes in rats. In addition, dates increase insulin secretion, decreases insulin resistance and inhibit alpha glucosides and amylase activity and thus by retarding the hydrolysis of carbohydrates it helped in treatment of diabetes mellitus. ${ }^{25}$

In view of above observations, protective effcts of both seeds and fruit of Ajwa date may be attributed due to the presence of strong antioxidants and other phytoelements.

\section{Conclusion}

Study displays that Ajwa date (phonex dactylefera) facilitated alleviation of renal deterioration by protecting the tubular, vascular and glomerular structures from oxidative damage. Treatment with Ajwa seed diet significantly reduced relative kidney weight, glomerular diameter and histological features of diabetic kidney. Further studies are required for the detection and isolation of key components which are responsible for nephroprotective effect. Human studies and studies on other diabetic complications may be conducted with varying doses and duration of Ajwa seed and fruit.

\section{Conflict of Interest: None}

\section{References}

1. Sulaiman MK. Diabetic nephropathy : recent advances in pathophysiology and challenges in dietary management. Diabetol Metab Syndr [Internet]. 2019; $1-5$.

2. Haneda M, Utsunomiya K, Koya D, Babazono T, Moriya T, Makino H, et al. A new Classification of Diabetic Nephropathy 2014: A report from Joint Committee on Diabetic Nephropathy. J Diabetes Investig. 2015;6(2):242-6.

3. Satchell SC, Tooke JE. What is the mechanism of microalbuminuria in diabetes: A role for the glomerular endothelium? Diabetologia. 2008; 51(5): 71425.

4. Ullah A. Diabetes mellitus and oxidative stress - A concise review. Saudi Pharm J [Internet]. 2016; 24(5): 547-53.
5. Furuichi K, Shimizu M, Okada H, Narita I, Wada T. Clinico-pathological features of kidney disease in diabetic cases. Clin Exp Nephrol [Internet]. 2018; 22(5):1046-51.

6. Salehi B, Ata A, Kumar NVA, Sharopov F, Ram K, Ruiz-ortega A, et al. Antidiabetic Potential of Medicinal Plants and Their Active Components. 2019.

7. El-Fouhil AF, Ahmed AM, Darwish HH. Hypoglycemic effect of an extract from date seeds on diabetic rats. Saudi Med J. 2010;31(7):747-51.

8. Ali SAE, Hussein D, Abdelaziz A. The protective effect of Date seeds on Nephrotoxicity Induced by Carbon Tetrachloride in Rats. 2014;26(12):62-8.

9. Abdelaziz DHA, Ali SA, Mostafa MMA. Phoenix dactylifera seeds ameliorate early diabetic complications in streptozotocin-induced diabetic rats. Pharm Biol [Internet]. 2015;53(6):792-9.

10. Ahmad M, Zafar M, Sultana S. Fruit Plant Species Mentioned in the Holy Qura ' $n$ and Ahadith and Their Ethnomedicinal Importance Faculty of Pharmacy Gomal University, Dera Ismail Khan, Pakistan. Ethnomedical Study. 2009;5(2):284-95.

11. Suvarna, S.K., Layton, C. \& Bancroft JD. Bancroft's Theory and Practise of Histological Techniques. 7th ed.,. China: Churchill Livingstone Elsevier; 2013.

12. Nobrega M a., Fleming S, Roman RJ, Shiozawa M, Schlick N, Lazar J, et al. Initial Characterization of a Rat Model of Diabetic Nephropathy. Diabetes. 2004;53:735-42.

13. Johora F, Sadat A, Nurunnabi M, Shahriah S, Ahmed R. “W. 2014;9(1):11-6.

14. Pourghasem M, Nasiri E, Shafi H. Early renal histological changes in alloxan-induced diabetic rats. Int J Mol Cell Med [Internet]. 2014;3(1):11-5.

15. Ali A, Abdu S. Antioxidant Protection against Pathological Mycotoxins Alterations on Proximal Tubules in Rat Kidney. Funct foofs Heal Dis. 11AD; 4: 11834.

16. Ali SAE, Hussein D, Abdelaziz A. by Carbon Tetrachloride in Rats. 2014;26(12):62-8.

17. Al-Qarawi AA, Abdel-Rahman H, Mousa HM, Ali BH, El-Mougy SA. Nephroprotective action of Phoenix dactylifera in gentamicin-induced nephrotoxicity. Pharm Biol. 2008;46(4):227-30.

18. Mbark AN, Bouhlali E dine T, Zegzouti YF, Ennassir J, Alem C, Benlyas M. Phytochemical compositions and antioxidant capacity of three date ( Phoenix dactylifera L.) seeds varieties grown in the South East Morocco. J Saudi Soc Agric Sci [Internet]. 2015; 16(4):350-7. 
19. Harthi SS Al, Pharm B, Mavazhe A, Pharm B, Mahroqi H Al, Sc M, et al. Quantification of phenolic compounds, evaluation of physicochemical properties and antioxidant activity of four date ( Phoenix dactylifera L .) varieties of Oman. J Taibah Univ Med Sci [Internet]. 2015;10(3):346-52.

20. Ahmed A, Arshad MU, Saeed F, Ahmed RS, Chatha SAS. Nutritional probing and HPLC profiling of roasted date pit powder. Pakistan J Nutr. 2016; 15(3): 229-37.

21. Khalid S, Ahmad A, Kaleem M. Antioxidant activity and phenolic contents of Ajwa date and their effect on lipo-protein profile. 2017;7(6):396-410.

22. Abdul-Hamid NA, Mustaffer NH, Maulidiani M, Mediani A, Ismail IS, Tham CL, et al. Quality evaluation of the physical properties, phytochemicals, biological activities and proximate analysis of nine Saudi date palm fruit varieties. J Saudi Soc Agric Sci [Internet]. 2018;
23. Khalid S, Khalid N, Khan RS, Ahmed H, Ahmad A. A review on chemistry and pharmacology of Ajwa date fruit and pit. Trends Food Sci Technol [Internet]. 2017;63(March):60-9.

24. Crascì L, Lauro MR, Puglisi G PA. Natural antioxidant polyphenols on inflammation management: Anti-glycation activity vs metalloproteinases inhibition. Crit Rev food Sci Nutr. 2018;58(6):893-904.

25. Al-zuhair S, Dowaidar A, Kamal H. Inhibitory effect of dates-extract on $\alpha$-Amylase and $\alpha$-glucosidase enzymes relevant to non-insulin dependent diabetes mellitus. J Biochem Technol. 2010;2(2):158-60.
Authors Contribution
II: Conceptionlization of Project
II,MM: Data Collection
II,NF,AM,AW: Literature Search
II,AM,AW: Statistical Analysis
II,NF: Drafting, Revision
II,MM,AM,AW: Writing of Manuscript 